
\title{
25 Research Square \\ Prevalence of Porcine Pseudorabies Virus and Its Coinfection Rate in Heilongjiang Province in China from 2013 to 2018
}

\author{
Han Zhou \\ Northeast Agricultural University \\ Yan Pan \\ CP Group \\ Mengda Liu \\ Shandong Agricultural University \\ Zifeng Han ( $\boldsymbol{\nabla}$ zifeng.han@fao.org ) \\ Food and Agriculture Organization of the United Nations https://orcid.org/0000-0001-6907-6570
}

\section{Research article}

Keywords: Pseudorabies virus, veterinary epidemiology, coinfection rate, Heilongjiang province

Posted Date: August 9th, 2019

DOl: https://doi.org/10.21203/rs.2.12447/v1

License: (9) (i) This work is licensed under a Creative Commons Attribution 4.0 International License. Read Full License

Version of Record: A version of this preprint was published at Viral Immunology on October 1st, 2020. See the published version at https://doi.org/10.1089/vim.2020.0025. 


\section{Abstract}

Background Pseudorabies (PR) is a highly contagious disease affecting a wide range of animals worldwide, which causes great annual economic losses in China. In this study, a total number of 18815 serum samples and 1589 tissue samples were tested by ELISA and PCR, which were collected from 311 intensive pig farms ( $\geq 350$ sows) located in eight cities in Heilongjiang province. Results Overall, $16.3 \%$ and $84.5 \%$ serum samples were positive for gE- and gB-specified ELISA, respectively. $17.8 \%$ of tissue samples were shown as PCR positive for PRV. The coinfection rates of PRV with porcine reproductive and respiratory syndrome virus (PRRSV), porcine circovirus type 2 (PCV2), and classical swine fever virus (CSFV) were measured. The rate of PRV co-infected with PRRSV was $36.0 \%$ followed by $12.9 \%$ with PCV2 and $1.8 \%$ with CSFV, respectively. Conclusions These results clearly demonstrate PRV prevalence and its coinfection rate in Heilongjiang province indicating high PR endemic in pig farms in this region. This study provides data for further epidemiological investigations and a reference for developing PRV control strategies in this region and in China.

\section{Background}

Pseudorabies (PR), also known as Aujeszky's disease, is an economically crucial viral disease of pigs and other animals worldwide. It is caused by the Pseudorabies virus (PRV), which is a member of genus Varicello virus of the subfamily Alphaherpesviridae within the family Herpesviridae. While PRV can infect numerous species of animals including ruminants and rodents [1,2], pigs are recognized as the primary host as well as act as the only reservoir and latent carrier of the PRV [3]. PRV infected pigs are commonly characterized by fatal infections in piglets, growth retardation in growing pigs, and respiratory disorders, encephalomyelitis, reproductive failure in sows $[1,4]$.

PRV was firstly discovered in 1902. The first report of PRV infection in China was back to the 1950s [5]. From 1990s to late 2011, PR was well controlled resulting from the adaptation of the Hungary-origin gpl-negative vaccine strain Bartha-K61 in most of pig farms in China. Lower level of morbidity and mortality was observed in newborn piglets. It was recorded that PRV has been eradicated from domestic pigs in many western countries. gEdeleted vaccine plays a pivotal role in combating PRV in these free countries, particularly in terms of differentiating infected animals from vaccinated counterparts [6, 7].

However, in late 2011, a PR outbreak characterized by neurological disorders and high mortality in piglets was identified in many of Bartha-K61-vaccinated pig farms, which rapidly spread to most of regions in China $[5,8]$. This re-emergence indicated that the Bartha-K61-vaccine may not able to provide effective protection against the variant PRV (vPRV) infection. Data on epidemiology of PRV and its coinfection rate with other major swine diseases may be of great importance for prevention and control of vPRV, particularly in regions had dense pig population.

Heilongjiang province located in the northeast of China sharing the border with Russia, which has massive pig farms and a large amount of pig population. To date, the total population of pigs and sows was estimated to be approximately 28 million and 3 million in Heilongjiang in 2017. Although PRV outbreaks have been reported in most of provinces in China, no systematic studies have been carried out to investigate the epidemiology of the disease in intensive pig farms in Heilongjiang province on an annual basis. The goal of this study was to understand PRV prevalence and its coinfection rates by investigating 18815 serum samples and 1589 tissue samples collected from 311 pig farms in eight cities in Heilongjiang province from 2013 to 2018. PRV gB- and gE- 
antibody level, positive rate of PRV, and coinfection rates of PRV with other major swine viral diseases were analyzed. Our results suggest that PRV is highly prevalent in the region as a major threat to pig breeding industry in Heilongjiang province.

\section{Results}

\section{Sero-prevalence rate (SPR) of PRV-gB and PRV-gE}

In this study, 18815 serum samples of pigs in different production phases were collected from pig farms in eight investigated cities in Heilongjiang province (Fig. 1). Samples were subsequently examined by ELISA on an annual basis to investigate gB- and gE-specific antibody level and sero-prevalence rate (SPR). More than $80 \%$ of pigs were vaccinated in the investigated farms in Heilongjiang province, according to the higher level of PRV-gB SPR rates described in Table 1 from 2013 to 2018. Moreover, as shown in Table, S/N ratio of different investigated herds showed lower than 0.6 ranging from 0.17 to 0.54 indicating high gB-antibody levels in different herds in the region.

As shown in Table 3, independent of investigated herds, the average SPR of PRV-gE of pigs was 16.3\% and showed a decrease from $20.9 \%$ in 2013 to $11.6 \%$ in 2018 . There is a similar trend, gradual decrease, of SPR of PRV-gE observed in different investigated herds throughout the investigation period, with the exception of year 2015 showing higher SPR of PRV-gE in fattening pigs, replacement pigs, and piglets compared to that of in 2014.

\section{Positive rate of PRV and its coinfection}

1589 tissue samples were detected by RT-PCR. Results in Table 4 showed that the average positive rate of PRV was $14.1 \%$ (225/1589) in Heilongjiang province during the investigation period of time. The overall positive rate of PRV was the highest at 17.8\% in 2013 (39/209) and gradually decreased at 11.5\% in year 2018 with approximately rate at $14.1 \%$ (Table 4 ).

The co-infection of PRRSV, PCV2 and CSFV was detected in all 225 PRV-positive samples. Results were shown in Table 5categorized by investigated cities. In this study, 36.0\% (81/225) of PRV positive pigs were co-infected by PRRSV, followed by $12.9 \%(29 / 225)$ by PCV2, and $1.8 \%(4 / 225)$ by CSF. The co-infection rates of PRV and PRRSV were over $40 \%$ in Harbin (18/34) and Jiamusi (14/35).

\section{Discussion}

PR was recognized as a major threat to the swine industry in China. It was listed in "Mid- and Long-term Animal Disease Prevention and Control Program in China" targeting on eradicating PR in pig farms in China by the end of 2020 [9, 10].Since 2011, a PRV eradication program has been launched at national level, which is being implemented in most of pig farms, especially intensive farms, in Heilongjiang Province. Previous studies have indicated that the positive rate of PRV-gE in breeding farms in different regions of China have outweighed over $50 \%$ and up to $90 \%[11,12]$. However, there is no published information available on PR in Heilongjiang province. This study therefore was designed to investigate PRV prevalence and its confection rates with other major swine viral diseases in Heilongjiang province. To the best of our knowledge, this is the first study reporting pig farm PRV prevalence and its coinfection rate in the region. 
In this study, 18,815 serum samples of pigs in different production phases were collected from pig farms in eight investigated cities in Heilongjiang province, and were subsequently examined by ELISA on an annual basis to investigate gB- and gE-specific antibody level and sero-prevalence rate (SPR).Consistent with results of previous publications [10,13-15], more than $80 \%$ of pigs were vaccinated in the investigated farms in Heilongjiang province, according to the higher level of PRV-gB SPR rates described in Table 1 from 2013 to 2018. Moreover, S/N ratio of different investigated herds showed lower than 0.6 ranging from 0.17 to 0.54 . Results indicated that the immunization density of PRV and gB-antibody level were considerably high in Heilongjiang province, which was expected to provide effective prevention and control against PRV infection.

The SPR of gE in all investigated herds of sows, boars, fatting pigs, replacement pigs, and young piglets showed similar following the same trend, a gradual decrease from 2013 to 2018 . There was an exception, a slight increase of SPR of gE observed, in fatting pigs, replacement pigs, and young piglets in 2015 compared to that of 2014 probably due to local temperature variation. Consistent with results of PRV-gE, the overall positive rate of PRV showed a trend of gradually decrease from 2013 to 2018 (Table 4). Previous studies conducted in Shandong province in China have shown that a high proportion of pigs were latently infected by PRV in the investigated region $[16,17]$, which was recognized to be the most critical source of infection when the latent viral genome is reactivated [5]. Heilongjiang province was recorded significant lower temperature than that of Shandong province, which may contribute to PRV prevention and control and its further spread in the region. Our results demonstrated a trend of decline of gE SPR and PRV positive rate during the period of investigation, from 2013 to 2018, resulting from the development of vaccines based on the epidemic PRV strains, the scale of selected pig farms, and a geographical factor. It therefore can be safely concluded that vaccination is of by no means unimportant for PRV prevention and control, current vaccines applied in the field in the region may provide effective protection against PRV infection. It is of also necessary to take other forceful measures [12] to provide further control of PRV, including strengthening biosecurity management, animal monitoring, identification and removal of the latent carriers, and so forth.

It is not uncommon for pigs identified as concurrent infection with more than one pathogen under current intensive swine breeding system. Previous studies reported that pigs can be co-infected by PRV with a wide range of pathogens, such as PRRSV, CSF, PCV2, Streptococcus spp., etc [9]. In this study, 36.0\% of PRV positive pigs were co-infected by PRRSV, subsequently followed by PCV2 (12.9\%) and CSF (1.8\%), respectively (Table 5). It was reported that there was a higher rate of concurrence of PRRS in the winter [18], combined with seasonal factor in Heilongjiang, which may be considered as a possible reason of higher rate of PRV and PRRSV coinfection. Our findings reveal the high frequency of coinfection of PRV associated with PRRSV in Heilongjiang Province.

Limitation of this study may skew the results, requiring cautions during interpretation. Firstly, the investigated pig farms are only intensive farms in eight major cities in the region, so that the results of this study could not be used to draw a comprehensive conclusion on the PRV situation of the whole province. Secondly, the majority of samples were not equally collected in each month of the investigated five years due to logistic constraints, seasonal variation therefore may slightly influence the prevalence and coinfection rate reported.

\section{Conclusion}

The results of this study clearly demonstrate the prevalence of PRV and its co-infection rate in intensive pig farms in Heilongjiang province and widespread. Current available vaccines may provide effective protection against PRV infection. A comparative majority of PRV infected pigs in Heilongjiang province were shown to be coinfected with 
PRRSV, which should be recognized as a crucial factor during the design of PRV disease control programs and its further eradication.

\section{Methods}

\section{Sampling strategy}

A cross sectional study was carried out in 311 intensive pig farms from eight cities in Heilongjiang province. A total number of 18815 samples were collected to determine the seroprevalence of PRV. In this study, blood samples were collected from the precaval vein of pigs from January 2013 to August 2018. In this study, all pigs were released after sampling. Serum samples were categorized by sow, boar, fatting pig, replacement pig, and piglets. Based on the number of sero-positive samples in each investigated city, 1589 tissue samples were randomly selected to detect positive rate of PRV and its coinfection rate with PRRSV, CSF, and PCV2, respectively, by using PCR.

\section{Sample collection and ELISA}

A total number of 18815 serum samples were collected from eight main geographic citiess of Heilongjiang province, which are Harbin, Jiamusi, Qiqihar, Suihua, Hegang, Daqing, Mudanjiang, and Jixi. Anti-gB and -gE antibody levels of investigated samples were determined by using a commercial ELISA kit (IDEXX Laboratories, Westbrook, ME, USA) according to the manufacturer's instructions to differentiate the vaccine strain from field strains.

\section{Real time PCR}

1638 tissue samples from different pig farms were selected. Tissue samples (lymph node, kidney, spleen and brain) were determined for PRV, PRRSV, PCV2, and CSF by using commercial RT-PCR kits (Beijing Anheal Laboratories, Beijing China) according to the manufacturer's instructions.

\section{Abbreviations}

CSV Classical swine fever virus; ELISA Enzyme-linked immunosorbent assay; PCR Polymerase chain reaction; PCV2 Porcine circovirus type 2; PR Pseudorabies; PRV Pseudorabies virus; PRRSV Porcine reproductive and respiratory syndrome virus; SPR Sero-prevalence rate; vPRV variant Pseudorabies virus

\section{Declarations}

\section{Ethics approval and consent to participate}

The protocol of this study was approved by the Ethic Committee on the animals of Northeast Agriculture University. Consent to participate has been obtained by all farm owners.

\section{Consent for publication}




\section{Availability of data and material}

The data used to support the findings of this study are included in this published article.

\section{Competing interests}

The authors declare that there are no competing interests.

\section{Funding}

This work was supported by the National Natural Science Foundation of China (Grant No. 31602066) and Heilongjiang PostDoctoral Financial Assistance (LBH-Z16017). The funders did not play any role in the design, conclusions or interpretation of the study.

\section{Permission from the farm owners}

The authors declare that this study has obtained permissions from all the owner of the investigated farms.

\section{Authors' contribution}

$\mathrm{ZH}, \mathrm{ML}$ and $\mathrm{HZ}$ conceived and designed the experiments; YP performed the experiments with the help of $\mathrm{ZH}$ and $\mathrm{HZ}$; ZH, ML and $\mathrm{HZ}$ analyzed the data; $\mathrm{ZH}$ and $\mathrm{HZ}$ wrote the paper. All authors read and approved the final manuscript.

\section{Acknowledgement}

The authors are very thankful to Ms Mengying Li and Ms Qianying Zhang for their excellent technical assistance and support.

\section{References}

1. Mettenleiter TC. Aujeszky's disease (pseudorabies) virus: the virus and molecular pathogenesis-state of the art, June 1999. Vet Res. 2000; 31(1):99-115.

2. Pomeranz LE, Reynolds AE, Hengartner CJ. Molecular biology of pseudorabies virus: impact on neurovirology and veterinary medicine. Microbiol Mol Biol Rev. 2005; 69(3):462-500.

3. Crandell RA. Pseudorabies (Aujeszky's disease). Vet Clin North Am Large Anim Pract. 1982; 4(2):321-331.

4. Rziha HJ, Mettenleiter TC, Ohlinger V, Wittmann G. Herpesvirus (pseudorabies virus) latency in swine: occurrence and physical state of viral DNA in neural tissues. Virology. 1986; 155(2):600-613. 
5. An TQ, Peng JM, Tian ZJ, Zhao HY, Li N, Liu YM, Chen JZ, Leng CL, Sun Y, Chang D, Tong GZ. Pseudorabies virus variant in Bartha-K61-vaccinated pigs, China, 2012. Emerg Infect Dis. 2013; 19(11):1749-1755.

6. Muller T, Hahn EC, Tottewitz F, Kramer M, Klupp BG, Mettenleiter TC, Freuling C. Pseudorabies virus in wild swine: a global perspective. Arch Virol. 2011; 156(10):1691-1705.

7. Smith G. Preferential sexual transmission of pseudorabies virus in feral swine populations may not account for observed seroprevalence in the USA. Prev Vet Med. 2012; 103(2-3):145-156.

8. Tong W, Li G, Liang C, Liu F, Tian Q, Cao Y, Li L, Zheng X, Zheng H, Tong G. A live, attenuated pseudorabies virus strain JS-2012 deleted for $\mathrm{gE} / \mathrm{gl}$ protects against both classical and emerging strains. Antiviral Res. 2016; 130:110-117.

9. Sun Y, Luo Y, Wang CH, Yuan J, Li N, Song K, Qiu HJ. Control of swine pseudorabies in China: Opportunities and limitations. Vet Microbiol. 2016; 183:119-124.

10. Hu D, Lv L, Zhang Z, Xiao Y, Liu S. Seroprevalence and associated risk factors of pseudorabies in Shandong province of China. J Vet Sci. 2016; 17(3):361-368.

11. Liu Y, Zhang S, Xu Q, Wu J, Zhai X, Li S, Wang J, Ni J, Yuan L, Song X, Zhao B, Zhou Z, Wang C, Yang L. Investigation on pseudorabies prevalence in Chinese swine breeding farms in 2013-2016. Trop Anim Health Prod. 2018; 50(6):1279-1285.

12. Wu R, Bai C, Sun J, Chang S, Zhang X. Emergence of virulent pseudorabies virus infection in northern China. J Vet Sci. 2013; 14(3):363-365.

13. Wang Y, Qiao S, Li X, Xie W, Guo J, Li Q, Liu X, Hou J, Xu Y, Wang L, Guo C, Zhang G. Molecular epidemiology of outbreak-associated pseudorabies virus (PRV) strains in central China. Virus Genes. 2015; 50(3):401-409.

14. Song C, Gao L, Bai W, Zha X, Yin G, Shu X. Molecular epidemiology of pseudorabies virus in Yunnan and the sequence analysis of its gD gene. Virus Genes. 2017; 53(3):392-399.

15. Xia L, Sun Q, Wang J, Chen Q, Liu P, Shen C, Sun J, Tu Y, Shen S, Zhu J. Epidemiology of pseudorabies in intensive pig farms in Shanghai, China: Herd-level prevalence and risk factors. Prev Vet Med. 2018; 159:51-56.

16. Gu J, Hu D, Peng T, Wang Y, Ma Z, Liu Z, Meng F, Shang Y, Liu S, Xiao Y. Epidemiological investigation of pseudorabies in Shandong Province from 2013 to 2016. Transbound Emerg Dis. 2018; 65(3):890-898.

17. Hu D, Lv L, Zhang Z, Xiao Y, Liu S. Seroprevalence and associated risk factors of pseudorabies in Shandong province of China. J Vet Sci. 2016; 17(3):361-368.

18. Albina E. Epidemiology of porcine reproductive and respiratory syndrome (PRRS): an overview. Vet Microbiol. 1997; 55(1-4):309-316.

\section{Tables}

Table 1 Seroprevalence rate of PRV-gB in Heilongjiang province from 2013 to 2018 


\begin{tabular}{clll} 
Year & Sample Numbers & Positive Numbers & SPR \\
\hline 2013 & 2968 & 2480 & $83.6 \%$ \\
\hline 2014 & 2880 & 2410 & $83.7 \%$ \\
\hline 2015 & 3402 & 3008 & $88.4 \%$ \\
\hline 2016 & 3086 & 2599 & $84.2 \%$ \\
\hline 2017 & 3748 & 3232 & $86.2 \%$ \\
\hline 2018 & 2731 & 2200 & $80.6 \%$ \\
\hline Total & 18815 & 15929 & $84.5 \%$
\end{tabular}

Table 2 Anti-glycoprotein B S/N ratios in different herds in Heilongjiang province from 2013 to 2018

\begin{tabular}{llllll} 
& Sows & Boars & Fatting pigs & Replacement pigs & Young piglets \\
\hline 2013 & 0.19 & 0.25 & 0.56 & 0.58 & 0.43 \\
\hline 2014 & 0.18 & 0.20 & 0.53 & 0.50 & 0.48 \\
\hline 2015 & 0.16 & 0.29 & 0.58 & 0.52 & 0.50 \\
\hline 2016 & 0.18 & 0.23 & 0.48 & 0.45 & 0.45 \\
\hline 2017 & 0.16 & 0.26 & 0.55 & 0.48 & 0.50 \\
\hline 2018 & 0.14 & 0.20 & 0.52 & 0.40 & 0.33 \\
\hline Total & 0.17 & 0.24 & 0.54 & 0.49 & 0.45
\end{tabular}

Table 3 Seroprevalence rate of PRV-gE in different herds in Heilongjiang province from 2013 to 2018 


\begin{tabular}{|c|c|c|c|c|c|c|c|c|}
\hline \multirow[t]{2}{*}{ Year } & \multicolumn{5}{|c|}{ Herds } & \multirow[t]{2}{*}{$\begin{array}{l}\text { Sample } \\
\text { Numbers }\end{array}$} & \multirow[t]{2}{*}{$\begin{array}{l}\text { Positive } \\
\text { Numbers }\end{array}$} & \multirow[t]{2}{*}{ SPR } \\
\hline & Sows & Boars & $\begin{array}{l}\text { Fatting } \\
\text { pigs }\end{array}$ & $\begin{array}{l}\text { Replacement } \\
\text { pigs }\end{array}$ & $\begin{array}{l}\text { Young } \\
\text { piglets }\end{array}$ & & & \\
\hline \multirow[t]{2}{*}{2013} & $23.8 \%$ & $20.6 \%$ & $23.2 \%$ & $18.5 \%$ & $15.5 \%$ & 2968 & 619 & $20.9 \%$ \\
\hline & $354 / 1489$ & $66 / 323$ & $34 / 146$ & $53 / 289$ & $112 / 721$ & & & \\
\hline \multirow[t]{2}{*}{2014} & $22.9 \%$ & $17.1 \%$ & $20.2 \%$ & $16.1 \%$ & $9.7 \%$ & 2880 & 519 & $18.0 \%$ \\
\hline & $305 / 1334$ & $64 / 374$ & $30 / 149$ & $53 / 328$ & $67 / 695$ & & & \\
\hline \multirow[t]{2}{*}{2015} & $20.2 \%$ & $15.5 \%$ & $21.2 \%$ & $17.6 \%$ & $11.5 \%$ & 3402 & 591 & $17.4 \%$ \\
\hline & $337 / 1668$ & $37 / 241$ & $36 / 172$ & $85 / 485$ & $96 / 836$ & & & \\
\hline \multirow[t]{2}{*}{2016} & $18.7 \%$ & $13.9 \%$ & $21.4 \%$ & $11.8 \%$ & $9.4 \%$ & 3086 & 474 & $15.4 \%$ \\
\hline & $293 / 1567$ & $38 / 272$ & $33 / 156$ & $38 / 325$ & $72 / 766$ & & & \\
\hline \multirow[t]{2}{*}{2017} & $18.3 \%$ & $11.3 \%$ & $18.7 \%$ & $10.7 \%$ & $8.8 \%$ & 3748 & 539 & $14.4 \%$ \\
\hline & $311 / 1697$ & $51 / 447$ & $46 / 246$ & $51 / 472$ & $80 / 886$ & & & \\
\hline \multirow[t]{2}{*}{2018} & $13.9 \%$ & $10.9 \%$ & $15.4 \%$ & $7.6 \%$ & $8.9 \%$ & 2731 & 318 & $11.6 \%$ \\
\hline & $172 / 1237$ & $35 / 325$ & $28 / 180$ & $26 / 344$ & $57 / 645$ & & & \\
\hline \multirow[t]{2}{*}{ Total } & $19.7 \%$ & $14.6 \%$ & $19.7 \%$ & $13.6 \%$ & $10.6 \%$ & 18815 & 3060 & $16.3 \%$ \\
\hline & 1772/8992 & $291 / 1982$ & $207 / 1049$ & $306 / 2243$ & $484 / 4559$ & & & \\
\hline
\end{tabular}

Table 4 Positive rate of PRV in Heilongjiang province from 2013 to 2018

\begin{tabular}{llll} 
Year & Sample numbers & Positive numbers & Positive rate \\
\hline 2013 & 219 & 39 & $17.8 \%$ \\
\hline 2014 & 221 & 36 & $16.3 \%$ \\
\hline 2015 & 236 & 38 & $16.1 \%$ \\
\hline 2016 & 235 & 32 & $13.6 \%$ \\
\hline 2017 & 287 & 35 & $12.2 \%$ \\
\hline 2018 & 391 & 45 & $11.5 \%$ \\
\hline Total & 1589 & 225 & $14.1 \%$
\end{tabular}

Table 5 Positive rate of PRV and its coinfection rate in different regions in Heilongjiang province from 2013-2018 


\begin{tabular}{llllll} 
City & City No./Total No. & & PRV+PRRSV & PRV+PCV2 & PRV+CSF \\
\hline Jiamusi & $35 / 225$ & $15.6 \%$ & 14 & 3 & 1 \\
\hline Harbin & $34 / 225$ & $15.1 \%$ & 18 & 5 & 0 \\
\hline Qiqihar & $31 / 225$ & $13.8 \%$ & 11 & 6 & 2 \\
\hline Suihua & $29 / 225$ & $12.9 \%$ & 7 & 3 & 1 \\
\hline Hegang & $28 / 225$ & $12.4 \%$ & 8 & 4 & 0 \\
\hline Daqing & $26 / 225$ & $11.6 \%$ & 9 & 4 & 0 \\
\hline Mudanjiang & $23 / 225$ & $10.2 \%$ & 9 & 2 & 0 \\
\hline Jixi & $19 / 225$ & $8.4 \%$ & 5 & 2 & 0 \\
\hline Total & 225 & & $81 / 225$ & $29 / 225$ & $4 / 225$ \\
& & & $36.0 \%$ & $12.9 \%$ & $1.8 \%$
\end{tabular}

Figures 


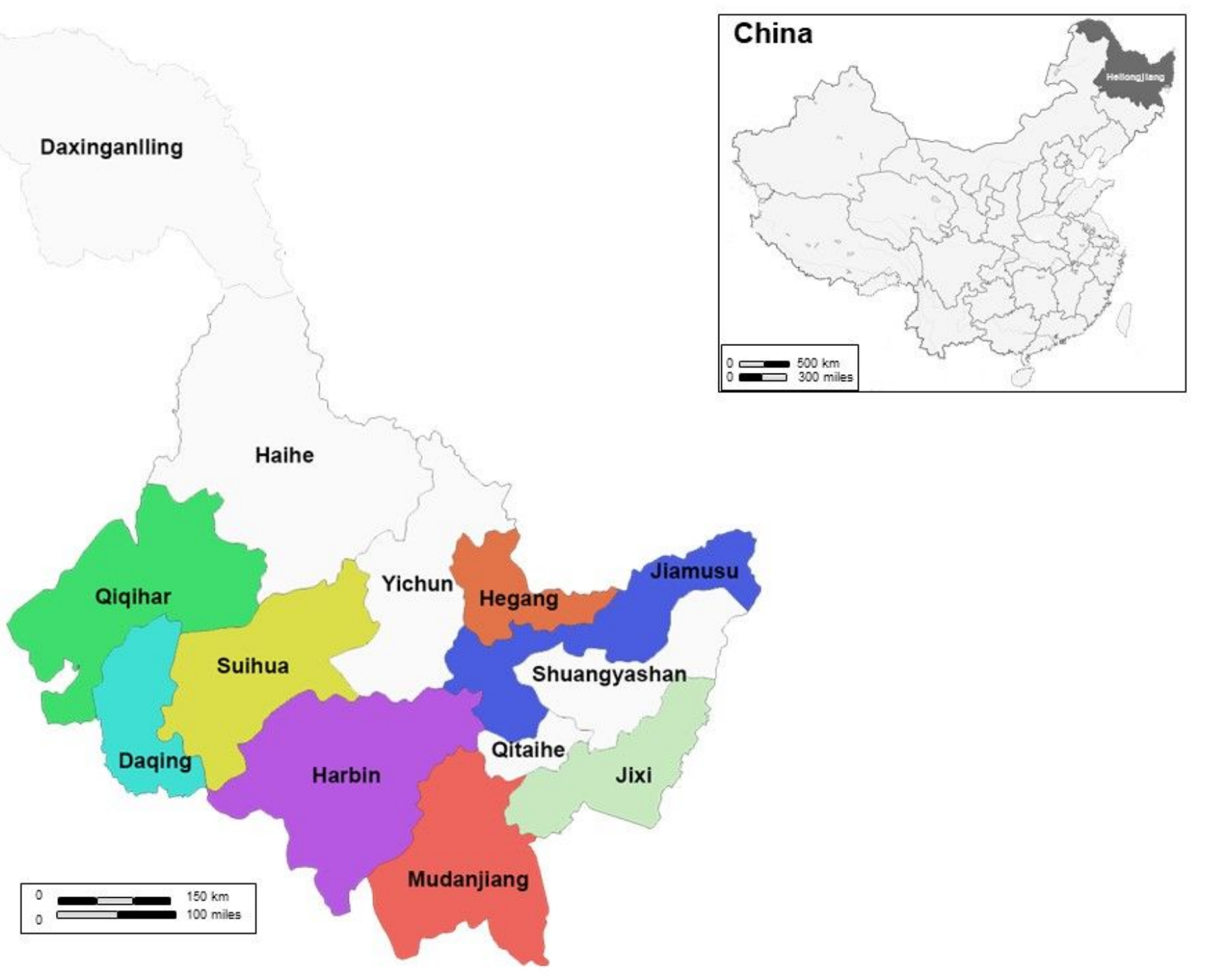

\section{Figure 1}

Location of Heilongjiang province on the map of China and investigated cities in the province. The image depicted in Figure 1 was prepared by the authors. Note: The designations employed and the presentation of the material on this map do not imply the expression of any opinion whatsoever on the part of Research Square concerning the legal status of any country, territory, city or area or of its authorities, or concerning the delimitation of its frontiers or boundaries. This map has been provided by the authors. 